\title{
O USO DE REDES SOCIAIS SEGMENTADAS NA PROMOÇÃO DE PRODUTOS CULTURAIS: UMA ANÁLISE DO CASO GETGLUE
}

\author{
SOCIAL MEDIA AS CULTURAL PRODUCTS PROMOTION PLATAFORM: \\ THE GETGLUE CASE
}

\section{EL USO DE LAS REDES SOCIALES EN LA PROMOCIÓN DE PRODUCTOS CULTURALES: UN ANÁLISIS DEL CASO GETGLUE}

\author{
Janaina de Holanda Costa Calazans \\ Doutora, Faculdade Boa Viagem \\ jcalazans@fbv.edu.br \\ Gêsa Karla Cavalcanti \\ Graduada, Faculdade Boa Viagem \\ gesakarla@hotmail.com \\ Rafael Lucian \\ Doutor, Faculdade Boa Viagem \\ rlucian@fbv.edu.br
}

\begin{abstract}
Resumo
Este artigo teve como objetivo realizar uma análise da divulgação de produtos culturais através de uma rede social segmentada, o GetGlue. Por serem mais segmentadas que as redes sociais comuns, essas redes temáticas são importantes para o desenvolvimento da interação dos usuários, e para as marcas, pois concentram um grupo de pessoas com interesses parecidos, permitindo a realização de ações mais pertinentes. Como método para realização dessa análise adotou-se uma pesquisa de natureza descritiva, a mesma foi composta pela realização de uma coleta de dados online onde foram selecionadas, seguindo critérios de data e dinâmica, as ações a serem analisadas, e em seguida foram realizadas duas distintas análises uma do conteúdo e outra da repercussão dessas ações. Para garantir a objetividade da análise de conteúdo foram determinadas categorias de análise que foram elaboradas a luz do referencial teórico. Concluiu-se, ao final, que o GetGlue é uma mídia diversa pelos vários tipos de inserções publicitárias que permite, e que a liberdade criativa dessa rede social ainda tem muito para oferecer.
\end{abstract}

Palavras-chave: Redes sociais. Promoção de produtos culturais. GetGlue 


\begin{abstract}
This article aims to perform an analysis of the dissemination of cultural products through a targeted social network, the GetGlue. Because they are more targeted to common social networks, these thematic networks are important for the development of the user interaction, and for brands, since they concentrate a group of people with similar interests, allowing the realization of actions most pertinent. The method adopted for conducting this analysis was a descriptive research, it was composed by conducting a data collection online which were selected according to criteria of date and dynamic actions to be analyzed, and then there were two one distinct analysis of content and other repercussions of these actions. To ensure the objectivity of content analysis categories of analysis were prepared light of the theoretical. It was concluded in the end that GetGlue is a diverse media by various types of advertising inserts that allows creative freedom and that this social network still has a lot to offer.
\end{abstract}

Key words: Social networks. Promotion of cultural products. GetGlue

\title{
Resumen
}

Este artículo tiene como objetivo realizar un análisis de la difusión de los productos culturales a través de una red social específica, el GetGlue. Debido a que son más orientado a las redes sociales comunes, las redes temáticas son importantes para el desarrollo de la interacción del usuario, y para las marcas, ya que concentran un grupo de personas con intereses similares, lo que permite la realización de las acciones más pertinentes. El método adoptado para la realización de este análisis fue una investigación descriptiva, se compone de llevar a cabo una recopilación de datos en línea que fueron seleccionados de acuerdo a criterios de fecha y acciones dinámicas que se deben analizar, y luego había dos un análisis distinto de contenido y otras repercusiones de estas acciones. Para garantizar la objetividad de las categorías de análisis de contenido de análisis se prepararon luz de lo teórico. Se concluyó al final que GetGlue es una diversidad de medios por diferentes tipos de inserciones de publicidad que permite la libertad creativa y que esta red social todavía tiene mucho que ofrecer.

Palabras clave: Redes sociales. La promoción de los productos culturales. GetGlue

\section{INTRODUÇÃO}

Em sua configuração inicial a plataforma web foi interpretada como uma ameaça às mídias tradicionais e aos produtos de entretenimento. Esse segundo encontrou riscos gerados pela possibilidade de produção e reprodução de conteúdos por meios clandestinos e em desrespeito com as leis de direitos autorais vigentes. O processo, então, de adaptação da indústria cultural, que tenta usar de forma positiva os recursos da Internet, foi um dos pontos de diferenciação da cibercultura.

Nesse ambiente online são produzidos conteúdos exclusivos que objetivam a criação e manutenção de uma fluência natural entre os meios tradicionais e digitais do produto. Um dos principais produtos a realizarem esse tipo de estratégia são as ficções seriadas que alternam 
entre os meios online e offline objetivando convergir todo esforço à TV. A temática, então deste trabalho aborda o fato de que as empresas produtoras de entretenimento evitaram criar estratégias baseadas em interação, fato tal que sugere uma limitação à interatividade devido a uma suposta falta de controle sobre a reação do público. Desta forma, o objeto de estudo da presente pesquisa é uma possível alternativa para essa problemática: as redes sociais segmentadas.

O objetivo central desse artigo, então, foi realizar uma análise da divulgação de produtos culturais através de uma rede social segmentada, o GetGlue. Para isso foram analisadas algumas ações realizadas por produtoras de entretenimento dentro do próprio GetGlue.

Para atingir tal objetivo foi necessário inicialmente realizar uma revisão teórica sobre as principais teorias abordadas, que é tema da próxima seção. Como método para realização dessa análise adotou-se uma pesquisa de natureza descritiva, a mesma foi composta pela realização de uma coleta de dados onde foram selecionadas, seguindo critérios de data e dinâmica, as ações a serem analisadas, e em seguida foram realizadas duas distintas análises uma do conteúdo e outra da repercussão dessas ações. Para garantir a objetividade da análise de conteúdo foram determinadas categorias de análise que foram elaboradas a luz do referencial teórico.

\section{REFERÊNCIAL TEÓRICO}

Antes da realização da análise foram apresentados alguns dos principais embasamentos teóricos relacionados a rede sociais e indústria cultural na cibercultura, como a conceituação e considerações de Adorno e Horkheimer (1947) sobre a indústria cultural, a adaptação desses conceitos para o ambiente online realizada por Duarte (2010) e ainda a questão da cibercultura e formação de uma cultura recombinante na Internet.

\subsection{Indústria Cultural}

O termo indústria cultural foi instituído pelos teóricos em comunicação da Escola de Frankfurt, Adorno e Hokeheimer (1947) em meados do século XX, e surgiu como crítica à inexpressividade do termo massmedia.

Define-se indústria cultural como o conjunto de meios de comunicação como, o cinema, o rádio, a televisão, os jornais e as revistas, que formam um sistema poderoso para 
gerar lucros e por serem mais acessíveis às massas, exercem um tipo de manipulação e controle social, ou seja, ela não só edifica a mercantilização da cultura, como também é legitimada pela demanda desses produtos (COSTA et al, 2003).

Para falar de indústria cultural é importante considerar a questão do tempo livre, algo que antecede a conceituação com relação a uma cultura de massa e que é de certa forma, responsável pela mesma. Para entender o conceito de tempo livre é preciso situar-se em um contexto histórico cronologicamente anterior ao do surgimento da imprensa, um tempo onde o homem não possuía o desejo de consumir bens que o distanciasse do trabalho, pois o mesmo não existia da forma que se conhece hoje. Esse momento é colocado por Duarte (2010) como Ancien Régime, e diz respeito à existência humana em um modo produtivo não industrializado, onde não havia a distinção tão demarcada, como percebemos, entre tempo livre e tempo de labuta. Essa distinção, segundo o autor, não existia na Idade média, onde o trabalho era realizado pelos vassalos em suas propriedades e os mesmos repassavam a produção menos sua cota para os suseranos. Foi só com a eliminação desse tipo de produção caseira e ocupação plena do modo produtivo capitalista que se pode notar a diferenciação entre o tempo destinado ao trabalho e o tempo de lazer

Existia sim um momento de pausa do trabalho, Duarte (2010) o destaca quando afirma que o trabalho no Ancien Régime era quase sempre sazonal, o que gerava um grande período de inatividade suprido por bailes e festas, e segundo o autor é nesse momento que nascem as noções de lazer e entretenimento, sendo o tempo livre algo distinto.

É o próprio modo feudal que impede a existência do tempo livre, pois só quando o trabalho deixa de ser uma atividade doméstica que faz parte do dia-a-dia de quem o realiza, e passa então a ser "mera condição de sobrevivência física" (DUARTE, 2010. p. 15), podemos abordar o conceito.

No modo de produção capitalista o tempo livre surge como uma forma de fuga da atividade de reificação que o operário executa todos os dias, no mesmo horário, no mesmo local. De acordo com Adorno (2002) o papel do tempo livre é desligar o indivíduo do trabalho para que no dia seguinte ele possa voltar ao mesmo com suas capacidades renovadas. E, até hoje os bens de entretenimento e lazer são assim vistos por aqueles que os consomem, o cinema no dia de folga é, por exemplo, o prêmio que o indivíduo dá a si mesmo por trabalhar a semana a inteira.

Essa relação de oposição que existe entre tempo livre e trabalho resulta no crescente interesse pelo consumo de bens de entretenimento e lazer, o que gera a necessidade da existência de algo que possa atender a esses desejos em grande escala: a indústria cultural. É 
importante destacar que pela sua produção grosseira de produtos idênticos para atender a demanda, a indústria cultural acaba por transformar, como afirma Adorno (2002), o tempo livre em uma paródia do seu conceito.

Além do inicial, e já citado, objetivo de atender as demandas que surgem com a disposição do tempo livre para o indivíduo da sociedade capitalista, a indústria cultural tornou-se um mecanismo bem mais desenvolvido que inclui, como firma Adorno (2002), o controle dos meios de comunicação de massa e a transmissão dos ideais da classe dominante.

Os principais representantes do conceito de indústria cultural, Horkheimer e Adorno (1947) colocam a mesma como um processo industrial estandardizado, ou seja, que gera produtos iguais em escala massiva, produtos esses que são rotulados como desejo do consumidor, mas que não passam de expressões da classe dominante. No ambiente onde os autores escreveram suas críticas sobre a indústria cultural, o próprio consumidor reforçava essa ideia de indústria que produz mais do mesmo, não por ações, e sim pela falta delas. Sendo assim, no estado atual, contextualizado pela internet e a cultura de vida digital, devem ser consideradas as mudanças com relação à capacidade produtiva do consumidor, bem como os esforços dessa indústria cultural na tentativa de estreitar os laços com o indivíduo receptor.

$\mathrm{Na}$ atualidade defende-se uma indústria cultural onde os conceitos de submissão do consumidor não são mais válidos, pois fora a liberdade do indivíduo destaca-se ainda sua capacidade de produção de bens. Tudo isso faz com que a massificação deixe de ser forçada ao consumidor, e a "indústria cultural passa cada vez mais a significar apenas indústria de cultura, perdendo seu aspecto original de algo depreciativo" (VIANA, 2009, p. 103).

\subsection{Cibercultura}

O ambiente pós-moderno, definido por Giddens (1990) como uma época de reorganização das instituições à falência dos discursos, coloca o homem dentro de uma nova configuração social, aonde consumo e produção de bens vão sendo alterados pelos avanços sociais e tecnológicos.

A modernidade tinha como utopia uma sociedade onde as relações comunicacionais seriam simples, rápidas e realizadas claramente. Ela partia do principio de globalização, da interligação de lugares e pessoas, da transformação do mundo em uma grande aldeia (MCLUHAN, 1967). Mas, não há nenhuma teoria que fale de forma fiel da repercussão e profundidade, em diversos aspectos, das mudanças que a sociedade sofreu e sofre para adaptar-se ao desenvolvimento das tecnologias da comunicação. 
Há sim uma aldeia global, mas dentro dela existem outras pequenas aldeias que segmentam a massificação da primeira e atestam o conceito de identidade social e individual. E a interação dentro dessas aldeias é muitas vezes mais profunda do que aquela que ocorre no todo (CAVALCANTI; LUCIAN, 2012).

É esse então o ambiente da cibercultura, um lugar propício a produções advindas das mais diversas fontes. Um lugar que possui diversas nomenclaturas, mas seja mundo digital ou a era da informação, os termos fazem referência ao mesmo desenvolvimento, eles falam de uma cultura de vida online, a cibercultura. Lemos (2010) define cibercultura como uma configuração sociotécnica onde haverá modelos tribais associados às tecnologias digitais, opondo-se ao individualismo da cultura do impresso, moderna e tecnocrática. Com a cibercultura, estamos diante de um processo de aceleração, realizando uma abolição do espaço homogêneo e delimitado por fronteiras geopolíticas e do tempo cronológico e linear, dois pilares da modernidade ocidental (LEMOS, 2010).

Uma definição do termo cibercultura possui inicialmente problemas relacionados às suas múltiplas significações. Considerando as mesmas, Lemos (2010) realiza sua definição enfatizando o lado social ao invés de apenas o tecnológico, sendo então a cibercultura o resultado da relação simbiótica entre sociedade, culturas e as novas tecnologias da microeletrônica.

O conceito de cibercultura engloba as práticas, técnicas, atitudes e comportamento intelectual dos integrantes do espaço em questão, a plataforma online ou ciberespaço (LEVY, 1999). Isso origina uma civilização virtual, que segundo Scheer (1996) parte do princípio de que as antigas bases daquela que chamamos de sociedade moderna foram substituídas por novas bases. Para ele, exército, família/produção, e religião, saem de cena dando lugar a computação, comunicação e internet. A sociedade virtual seria aquela onde a massa teria capacidade de produção de conteúdo, deixando assim de ser apenas mão de obra física.

Ainda segundo Scheer (1996), é a massa que dá subsidio à cibercultura, ela é o berço desse desenvolvimento cultural em rede, ou, de uma forma simplificada, a Cibercultura seria uma digitalização e update da cultura como conhecíamos. A tecnologia auxilia a realização de tarefas do dia-a-dia, trabalho, contas e outros e, em paralelo, as relações pessoais informais vão sendo transportadas para dentro das redes.

De acordo com Garcia (2005), a Internet não pode ser considerada como única responsável pelas mudanças que ocorrem juntamente com o processo de retribalização do homem, mas seu desenvolvimento acelerado é, de forma incontestável, o responsável pela disseminação e aumento das expectativas com relação à mesma. 
E, embora o desenvolvimento da cibercultura esteja, como coloca Lemos (2010), associado aos avanços em microeletrônica na década de 70 deve-se ainda considerar que o surgimento das estruturas base da sociedade da informação também estão apoiadas na condição de sociabilidade permitida pela pós-modernidade.

Para Lemos (2010), a cibercultura é recheada de novas maneiras de se relacionar com o outro e com o meio, ela não é uma simples substituição das formas anteriores de relação social, e sim o surgimento de inovadoras formas de relações mediadas. $\mathrm{O}$ autor explica ainda, que vários elementos de momentos culturais diferentes são agora recombinados, caracterizando assim a cibercultura. Esse processo de recombinação é para ele algo que sempre fez parte da cultura, mas que é reforçado pelo desenvolvimento das novas tecnologias da inteligência.

Considerando essa característica recombinante da cibercultura, Lemos (2009) define três princípios da mesma. Esse assunto será mais profundamente abordado quando o assunto em questão for a interação mediada por computador e os usuários, mas adianta-se que o primeiro principio destaca a capacidade de produção de conteúdo por parte de usuário, o segundo o compartilhamento dessa produção, e o terceiro trata da reconfiguração da indústria cultural massiva e das redes de sociabilidade da sociedade industrial, abordando ainda a crise no modelo produtivo da Indústria cultural.

Com base nos mesmos, pode-se entender a importância dos estudos e da apropriação de forma eficiente da internet por parte da indústria cultural. Acompanhar a produções, compartilhamentos e recombinações feitas pelos usuários é uma saída para a indústria da cultura, pois só o entendimento dessa nova relação pode levar à criação de novas estratégias.

\section{O CASO}

O GetGlue é uma rede social específica ou, como Bolsoni (2010) coloca uma rede temática. De acordo como o autor, essas redes não concorrem com as redes sociais mais usadas como Orkut e Facebook, e sim a complementam. Redes sociais desse tipo oferecem enfoque aos seus usuários, existem redes destinadas a músicas (lastfm), a séries (Orangotag), a contatos profissionais (Linkedin).

Por serem mais segmentadas que as redes sociais comuns, essas redes temáticas são importantes para o desenvolvimento da interação dos usuários, e para as marcas, pois concentram um grupo de pessoas com interesses parecidos, permitindo a realização de ações 
mais pertinentes. Como já citado na introdução desse trabalho, essas redes especificas oferecem uma produção especializada.

O uso do GetGlue se fundamenta na realização de check-ins e avaliações com relação a produtos culturais. Diferente das redes específicas mais comuns como Skoob, o GetGlue não se baseia apenas em um tipo de produto, nela o usuário pode fazer check-in em livros, seriados, filmes, álbuns musicais ou singles, telenovelas e outros. Atualmente, o GetGlue está na sua terceira versão que foi colocada no ar no final de setembro de 2012. Nela, apenas produtos televisivos são focados, devido ao interesse das produtoras em veicular dentro do GetGlue, mas as antigas páginas relacionadas a outros tipos de produtos ainda podem ser encontradas, assim como o usuário pode escolher usar a versão anterior do GetGlue.

A presença dentro do GetGlue é importante para as produções, principalmente as de séries televisivas que são as que mais investem dentro dessa rede social. Ilustra-se aqui essa repercussão através de pesquisa realizada pela GetGlue com relação à interação dentro da rede. Na imagem a seguir que expressa o Top 10 dos shows televisivos com maior quantidade de check-ins no verão de 2011.

\section{MÉTODO DE PESQUISA}

Para a realização do estudo aqui proposto determinou-se a realização de uma pesquisa descritiva, esse tipo de pesquisa, como propõe Gil (1999), objetiva a descrição das características de uma dada população ou fenômeno.

De acordo com Andrade (2002), a pesquisa descritiva tende a não incluir possíveis alterações do realizador, por isso "exige do pesquisador um delimitação precisa de técnicas, métodos, modelos e teorias que orientarão a coleta e interpretarão os dados, conferindo validade à pesquisa científica" (RAUPP; BEUREN, 2006).

Com base em um pesquisa exploratória previamente realizada com objetivo de entender o público do GetGlue, entende-se que a maioria dos usuários utilizam da rede social para fazer check-ins em produtos de ficção seriada, sendo assim a determinação do produto a ser analisadolimitou-se a séries com estreias durante o período da análise: The Walking Dead, Nikita,Happy Endings e Don't trust the B---- in Apartament 23. A decisão entre essas séries foi feita pelo ranking de check-ins do próprio GetGlue para prévias estreias das séries em questão.

De acordo com o trendropics de séries do GetGlue a série The Walking Dead foi a que possuía mais check-ins, logo, a mesma foi usada para análise dos check-ins e ações. The 
Wakling Dead é um seriado norte americano que está na sua terceira temporada, o plot da série é um mundo apocalíptico onde os últimos homens lutam por sua sobrevivência, a série é exibida nos Estados Unidos pela AMC e no Brasil pela FOX.

Foram então coletadas informações sobre as ações realizadas pela série The Walking Dead a fim de promover a estreia de sua terceira temporada na rede social GetGlue. O acesso as mesmas aconteceu através do próprio GetGlue e do blog de informações sobre essa rede social, o getlgue.com.

\subsection{Estratégia de análise do conteúdo das ações}

O objetivo da análise de conteúdo é analisar a ação em busca de check-ins, essa técnica tenta identificar categorias de análise pré-estabelecidas no material coletado. De acordo com Kassarjian (1977), a definição dessas unidades de conteúdo para analise é importante, pois mesmo as formas mais simples de análise de conteúdo requerem o julgamento do investigador nas decisões relacionadas aos dados.

A análise de conteúdo exige uma objetividade e por isso, como afirma Breselson (1952), as categorias de análise precisam ser definidas com muita precisão de forma que outros analistas possam aplicá-las ao mesmo corpo de conteúdo e garantir os mesmos resultados.

São então determinadas para essa parte da análise quatro unidades de conteúdo, são elas: inovação, interatividade, transmedia storytelling e convergência. A inovação diz respeito à forma como essas ações apresentam novas formas de contato entre público e conteúdo. Ela é de acordo com Luecke (2003) a personificação, combinação, ou síntese de conhecimento original, para avaliar e/ou valorizar novos produtos, processos ou serviços. Já a interatividade, como já explicado no decorrer desse trabalho, está relacionada às técnicas, usa-se aqui o conceito de Jenkins (2008), que afirma que a interatividade refere-se ao modo como as novas tecnologias são programadas para responder ao feedback do consumidor.

O conceito de transmedia storytelling também proposto pelo autor diz respeito à forma como a ação em análise dá continuidade ao conteúdo do produto divulgado. E a convergência está relacionada ao uso de características de outras mídias na ação, links para outras redes, elementos textuais ou de qualquer forma que façam menção, ou seja, links para outros pontos de informação sobre o produto. 


\subsection{Estratégia de análise da repercussão das ações}

Nesse ponto determina-se a forma de análise da atitude e do nível de imersão dos usuários com o produto determinado.

$\mathrm{Na}$ avaliação da forma como o consumidor reage à informação publicitária que o atinge ou aos produtos que consome é comum o uso do conceito de atitude do consumidor. $\mathrm{Na}$ análise comportamental do consumidor a atitude é vista segundo Schiffman e Kanuk (2000) como uma predisposição que é adquirida de maneira favorável ou desfavorável em relação a determinado objeto e que influencia o comportamento do consumidor Considera-se aqui uma classificação da atitude conforme sua valência que a coloca como positiva, negativa ou neutra. (ENGEl et. al, 2000). Sendo assim os textos serão analisados e classificados de acordo com a conotação positiva, negativa ou neutra que neles predomina. A análise do texto será feita com o intuito de identificar a satisfação, insatisfação ou indiferença pelo produto analisado, o seriado The Walking Dead, através das palavras, e símbolos usados pelos usuários.

Já a análise do nível de imersão será feita com base na classificação de fã apresentada por Hills (2002) em fã ativo e fã passivo, adiciona-se ainda o fanático proposto por Cunha (2012). Sendo um check-in de fã ativo aquele onde o usuário fala da série, do episódio, colocando suas considerações. De fã passivo quando apenas for feito check-in com uso de comentários padrões como "Esse episódio foi ótimo", "mal posso esperar pelo próximo episódio”. Já o fanático seria aquele que ao fazer check-in além de colocar suas considerações sobre o visto, defendem o show ou um determinado personagem, supõe teorias sobre desfechos, personagens. Abaixo são apresentados outros exemplos desses comentários padronizados.

\section{ANÁLISE DE DADOS}

Durante a análise de conteúdo tentou-se identificar as unidades de conteúdos determinadas: interatividade, convergência das mídias, inovação e transmedia storytelling nas ações da produtora do seriado The Walking Dead, AMC, no GetGlue.

Foram veiculadas no GetGlue três principais ações. A primeira delas era uma contagem regressiva para a estreia da terceira temporada da serie The Walking Dead, nela foram liberados seis diferentes adesivos, o primeiro deles seis dias antes da estreia e o último no dia da estreia. A segunda ação, também envolvendo adesivos, foi a "Season Premiere" um 
adesivo liberado para quem fizesse check-in durante a exibição do episódio. $\mathrm{E}$ a última foi a postagem dos web episodes e sneak peeks no feed de notícias do show. As peças foram analisadas individualmente.

\begin{tabular}{|c|c|c|c|}
\hline $\begin{array}{l}\text { Unidades de } \\
\text { Conteúdo }\end{array}$ & Porque? & O que dizem? & $\begin{array}{c}\text { Quem } \\
\text { Fundamenta? }\end{array}$ \\
\hline Inovação & $\begin{array}{l}\text { Entendimento das novas } \\
\text { formas de contanto entre } \\
\text { público e conteúdo. }\end{array}$ & $\begin{array}{l}\text { Combinação ou } \\
\text { síntese de } \\
\text { conhecimento original } \\
\text { para valorizar novos } \\
\text { produtos. }\end{array}$ & Luecke (2003) \\
\hline Interatividade & $\begin{array}{l}\text { Relaciona-se às técnicas } \\
\text { usadas para produção e } \\
\text { execução de ações na web } \\
2.0\end{array}$ & $\begin{array}{l}\text { As novas tecnologias } \\
\text { são programadas para } \\
\text { responder ao feedback } \\
\text { do consumidor. }\end{array}$ & Jenkins (2008) \\
\hline $\begin{array}{l}\text { Transmedia } \\
\text { strorytelling }\end{array}$ & $\begin{array}{l}\text { Forma de realização de } \\
\text { ação através de } \\
\text { desdobramentos } \\
\text { narrativos, propícia para } \\
\text { produtos de } \\
\text { entretenimento. }\end{array}$ & $\begin{array}{l}\text { Emprego de múltiplas } \\
\text { plataformas para } \\
\text { expressão de um } \\
\text { mundo ficcional. }\end{array}$ & Jenkins (2008) \\
\hline $\begin{array}{l}\text { Convergência das } \\
\text { mídias }\end{array}$ & $\begin{array}{l}\text { Uso de características de } \\
\text { outras mídias numa ação. }\end{array}$ & $\begin{array}{l}\text { Convergência permite } \\
\text { a fluidez midiática } \\
\text { entre diferentes meios. }\end{array}$ & Jenkins (2008) \\
\hline
\end{tabular}

Quadro 1: Unidades de Conteúdo

Fonte: Jenkins (2008); Luecke (2003) 


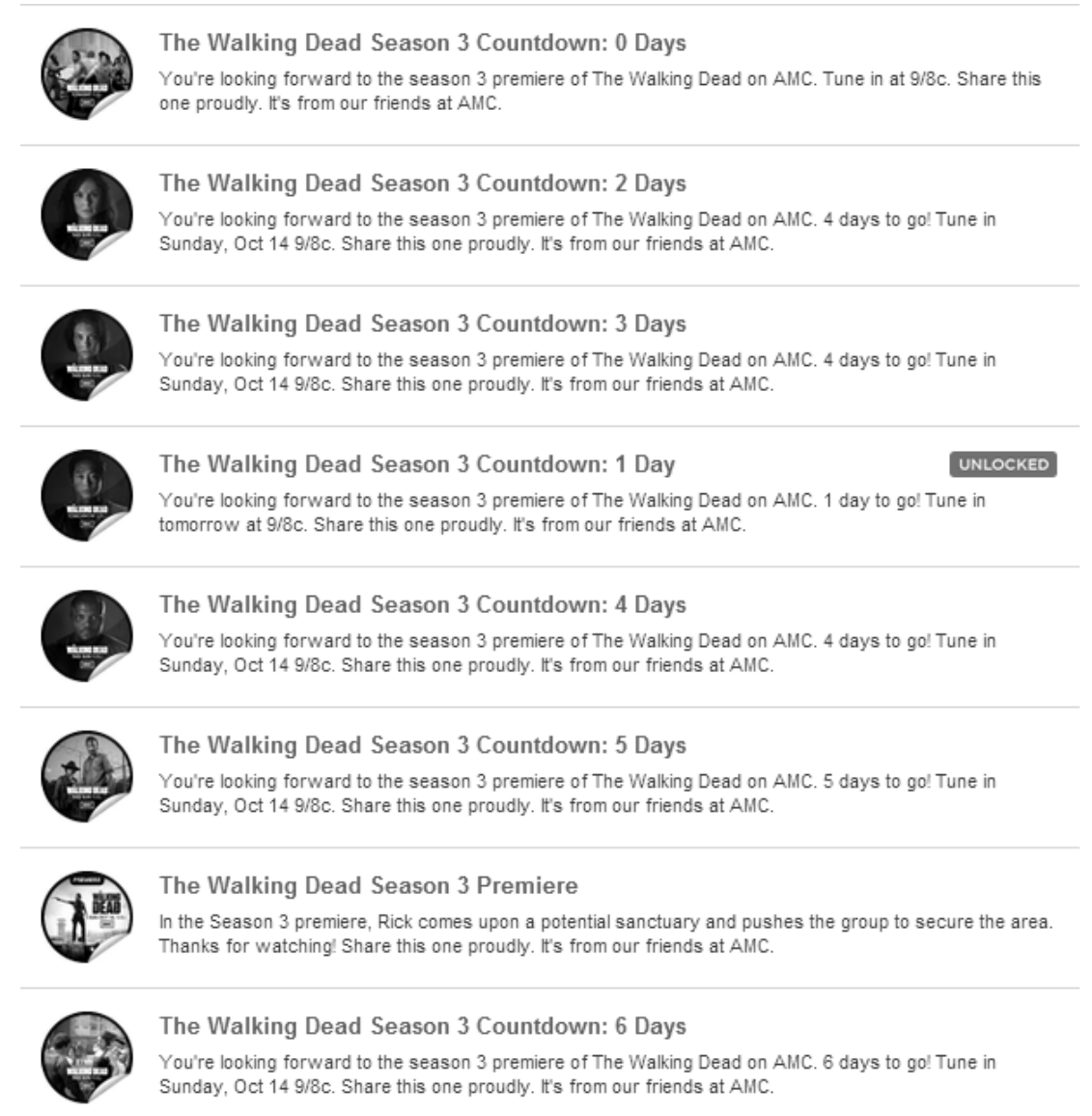

Figura 1: Adesivos liberados nas ações.

Fonte: http://o.GetGlue.com/stickers/

$\mathrm{Na}$ análise com relação à unidade de conteúdo interatividade foi percebida em $67 \%$ das peças veiculadas no GetGlue, o que indica que elas não possuíam muitas formas predefinidas para resposta do usuário, considerando que não são inclusas nesse momento as formas de interatividade inerentes à rede social.

A maioria das peças postadas era vídeos com web episodes, links para a página do show no site oficial da AMC, ou na fã page TalkingDead, um subproduto em formato de programa, onde os atores do show são entrevistados, são abordados temas como os episódios passados e normalmente são feitas explanações sobre os próximos acontecimentos no show.

Já a unidade de conteúdo convergência das mídias foi percebida na maioria das peças que apresentava links e elementos que faziam referências a outras plataformas, mas que, no geral, fluía para o consumo de informações sobre o produto principal.

Esse resultado aponta para uma preocupação da série em fazer o GetGlue um ponto do qual os usuários podem seguir para as páginas especificas do produto, como a fã page oficial, o TalkingDead, o aplicativo para Facebook The Walking Dead Social game e ainda algumas promoções do site da AMC. 
$\mathrm{Na}$ coleta de dados dessas peças buscou-se ainda encontrar peças de outras redes sociais que fizessem menção ao GetGlue, mas apenas no fã page oficial o seriado divulgou à ação de liberação de sticker no GetGlue.

Os critérios que caracterizavam a unidade inovação foram percebidos a maioria das peças integrantes da ação, principalmente porque cada adesivo trazia uma proposta diferente e eram exclusivos à plataforma GetGlue, sendo apenas divulgadas em outras redes. Já as outras ações também eram feitas na página destinada ao seriado The Walking Dead no site da AMC, e no Facebook oficial da série.

Quanto à transmedia storytelling, histórias paralelas à original, apenas os web episodes atenderam aos critérios de definição da mesma. Já que as outras ações apenas reproduziam conteúdos promocionais que não dão continuidade à narrativa.

Em relação à atitude dos respondentes com relação ao produto, percebeu-se que a maioria dos comentários é de caráter neutro, o que indica pouco envolvimento com dos usuários com o produto. Os check-ins considerados negativos seriam aqueles que criticam algum aspecto do show, os positivos os que elogiam.

Os resultados podem ainda indicar que a maioria dos respondentes só procuram utilizar o GetGlue após ou durante verem um determinado episódio se os acontecimentos no mesmo forem agradáveis a eles. Poucos usuários utilizam a rede para realizar comentários negativos.

Os usuários também foram classificados de acordo com o conteúdo de seus check-ins, os que possuíam texto, nas três principais tipologias de fãs apresentadas nesse trabalho: fã ativo, fã passivo e fanático. Quanto a isso percebeu-se que a maioria dos check-ins são advindos de fãs passivos, ou seja, eles apenas comentavam algo sobre algum aspecto do seriado ou episódio de forma superficial.

Não se pode afirmar com convicção através dos resultados obtidos que a maioria dos fãs que usam o GetGlue são passivos com relação ao produto em questão em qualquer plataforma, mas essa é uma das teorias que podem ser exploradas. Outra seria a de que independente de seres fãs ativos, passivos ou fanáticos os usuários não se envolvem nesse nível com o GetGlue. Nesse sentido seria mais sensato considerar que essa classificação é feita com relação tanto ao produto quanto ao GetGlue, evitando a generalização de que o usuário se envolvem da mesma forma com o produto em todo tipo de plataforma.

Nos check-ins coletados procurou-se ainda observar se houve repercussão dos mesmos, quanto a isso apenas $11,5 \%$ deles geraram interação de outros usuários. Esse resultado pode indicar que na maioria das vezes os usuários apenas se preocupam com a parte 
inicial do feed de notícias, eles fazem seus check-ins e terminam o uso, ou partem para outras páginas. Enquanto só uma pequena parcela deles olha o feed para ver o que outros acham sobre o produto. Esses comentários podem ser visto ao clicar-se no check-ins, na figura abaixo o check-in em cinza é o principal e o abaixo é a repostas de outro usuário a ele.

Os check-ins considerados repercussivos foram ainda analisados de acordo com o tipo de repercussão em participativa e não participativa o que indicou se nos mesmos os usuários que fizeram check-ins se preocupavam em responder aos comentários feitos em suas postagens. Percebeu-se então, que a maior parte dos usuários não realiza esse tipo de ação, o que indica desinteresse na interação com outros usuários.

\section{CONCLUSÃO}

Este trabalho realizou uma análise do uso de uma rede social segmentada para a disseminação de produtos culturais. Nesse sentido, a principal conclusão retirada das analises aqui realizadas é a de que o GetGlue é um ambiente propício para a disseminação de produtos televisivos e que rede sociais como essa funcionam como o diferencial que faz com que a televisão sobreviva à revolução das mídias, adequando-se à internet. Assim como acontece com a maioria dos produtos culturais.

Conclui-se então que o GetGlue é uma mídia diversa pelos vários tipos de inserções publicitárias que permite, e que a liberdade criativa dessa rede social ainda tem muito para oferecer. Um importante diferencial do Getglue com relação a outras redes sociais e ainda a outras redes segmentadas é que ele não deixas seu caráter de veículo tão explícito de modo a saturar o consumidor, ou seja, não são apresentadas na interface da rede propagandas como pop-ups, banners laterais e outros. Quanto à efetividade dessas ações com relação à convergência para a TV, conclui-se que as mesmas possuem um importante papel nesse fluxo, mas que ainda é preciso que as empresas produtoras explorem mais os recursos do GetGlue e ofereçam novos e diferenciados incentivos aos usuários.

Afirma-se ainda que a união das ações realizadas no GetGlue com as redes sociais Twitter e Facebook, no caso com as fã pages e perfis das marcas anunciantes nessas redes, o GetGlue pode trazer resultados mais eficientes para os anunciantes, principalmente para os estreantes.

Como limitação desse estudo aponta-se o fato de que a população de usuários do GetGlue é muito grande, e por isso na análise e resultados procura-se sempre reforçar a ideia de respondentes e não apenas de usuários. 
Como sugestão para futuros trabalhos propõe-se a realização de uma pesquisa sobre o uso do GetGlue mais aprofundada com relação aos fãs e mesmo a amostra. Propõe-se ainda a realização de pesquisas sobre o uso de outras redes temáticas para disseminação de produtos culturais.

\section{REFERÊNCIAS}

ADORNO, Theodor. Indústria Cultural e Sociedade. São Paulo: Paz e Terra, 2002. , Theodor. HORKHEIMER, Max. Dialética do esclarecimento. 1947. Disponível em<http://www.nre.seed.pr.gov.br/umuarama/arquivos/File/educesp/fildialeticaesclarec .pd f > Acesso em: 01 out. 2012.

ANDRADE, M. M. de. Introdução à Metodologia do Trabalho Científico.. São Paulo: Atlas, 2002.

BERELSON, B. Content Analysis in Communications Research. Illinois: The Free Press, 1952.

BOLSONI, Evandro. P. Sociabilidade em Redes Digitais Sociais Segmentadas: A reconstrução daidentidade virtual digital. Rio de Janeiro, UENF,2010 Disponível em: < http://www.pgcl.uenf.br/pdf/COGNICAO_6587_1308239209.pdf> Acesso em: 10. ago. 2012.

CAVALCANTI, Gêsa; LUCIAN, Rafael. Haven: Análise de Conteúdo da Narrativa Transmídia usada na divulgação do seriado. Disponível em < http://www.intercom.org.br/papers/nacionais/2012/resumos/R7-0946-1.pdf> Acesso em 10. Out. 2012.

CUNHA, Maria. A figura do fã enquanto criador. Universidade Católica Portuguesa, 2008. Disponível em: <http://www.bocc.ubi.pt/pag/cunha-ines-figura-fa-criador.pdf> Acesso em: 10 ago. 2012.

DUARTE, Rodrigo. Introdução à indústria Cultural. Rio de Janeiro: FGV, 2010.

ENGEL, James F., BLACKWELL, Roger D., MINIARD, Paul W. Comportamento do

Consumidor. Rio de Janeiro: LTC, 2000. 
GIDDENS, A. As consequências da modernidade. São Paulo: Unesp, 1990.

HILLS, Matt. Fan cultures. London: Routledge, 2002.

JENKINS, Henry. Cultura da convergência. São Paulo: Aleph, 2009.

LEMOS, A. Cibercultura: Tecnologia e Vida Social na Cultura Contemporânea. Porto Alegre: Sulina, 2002.

LEVY, Pierre As novas tecnologias da inteligência: o futuro do pensamento na era da informação. Rio de Janeiro: 34, 1993.

LUECKE, Richard. Managing Creativity and Innovation. Boston: Harvard Business Press, 2003.

KASSARJIAN, Harold. Content Analysis in Consume Research. The Journal of Consumer Research, Vol. 4, №1. Jun., 1997. Disponível em <http://www.jstor.org/ discover $/ 10.2307 / 2488631$ ?uid=3737664\&uid=2\&uid=4\&sid=21100733010791> Acesso em 08 set. de 2012.

MCLUHAN, Marshall. A Galáxia de Gutenberg. São Paulo: Editora da Universidade de São Paulo 1962.

SCHIFFMAN, Leon G.; KANUK, Leslie L. Comportamento do Consumidor . 9.ed. Rio de Janeiro: LCT, 2009. 
Original recebido em: 03/02/2009

Aceito para publicação em: Novembro de 2013

Rafael Lucian

Doutor em Administração pela UFPE (2012), autor do livro Sobrecarga de Informações: Um experimento no varejo eletrônico (Editora Universitária, 2008) e coautor dos livros Arenas da Comunicação com o Mercado (Editora Alameda, 2010), Marketing Online: Consumidor na Internet (Editora Universitária, 2009) e Integration and Innovation Orient to E-Society

(Spring, 2007). Atualmente é professor do curso de Comunicação Social (publicidade e propaganda) na DeVry/FBV.

Gêsa Karla Maia Cavalcanti

Bacharel em Comunicação pela DeVry/FBV (2012). Participa do grupo de extensão e pesquisa CEPAC e possui diversos artigos acadêmicos aceitos em congressos regionais, nacionais e internacionais.

Janaina de Holanda Costa Calazans

Doutora em Comunicação Social pela Universidade Federal de Pernambuco. Possui graduação em Comunicação Social (Jornalismo) pela Universidade Católica de Pernambuco (1999) e mestrado em Comunicação pela Universidade Federal de Pernambuco (2003). É professora titular e coordenadora do curso de Comunicação Social da Faculdade Boa Viagem; Coordenadora da Agência Experimental de Publicidade da FBV; Professora titular da Universidade Católica de Pernambuco. 